Türkiye Jeoloji Bülteni
Geological Bulletin of Turkey
$62(2019) 181-198$
doi: $1025288 / \mathrm{tj} b .567893$

\title{
Mollaresul Formasyonunun (Haymana-Ankara) Petrol Hazne Kaya Özellikleri
}

Petroleum Reservoir Properties of Mollaresul Formation (Haymana-Ankara)

\author{
Ayfer Özdemir $\mathbb{D}$ \\ Tarım ve Orman Bakanlı̆̆ı, Su Yönetimi Genel Müdürlüğü, \\ Alparslan Türkeş Cad. No:71 Söğ̈̈̈özü̈/Ankara
}

Geliş/Received : 26.01.2019 • Düzeltilmiş Metin Geliș/Revised Manuscript Received : 15.05.2019 • Kabul/Accepted : 17.05 .2019 • Bask1/Printed : 21.05 .2019 Araştırma Makalesi/Research Article Türkije Jeol. Bül. / Geol. Bull. Turkey

Öz: Petrol araştırma ve üretimi için rezervuar kalitesi hakkında detaylı araştırma yapmak, petrol arama ve değerlendirme çalışmalarının maliyetinin oldukça yüksek olması nedeniyle, maliyeti düşürmek için oldukça önemlidir. Bu çalışmanın amacı, Haymana-Polatlı havzası içerisinde yer alan Jura-Alt Kretase yaşlı kireçtaşlarından oluşan Mollaresul formasyonunun petrol hazne kaya kalitesini belirlemektir. Kireçtaşlarının rezervuar kalitesi, standart arazi çalışmaları ve laboratuvar analizleri yapılarak, gözeneklilik-geçirgenlik analizleri ve petrografik incelemeler yardımıyla ortaya konulmuştur. Arazi çalışmalarında formasyonun masif ve tabakalı olduğu düzeyler gözlenmiștir. İncelenen birim sığ denizel bir ortamdan gittikçe derinleșen deniz ortamında çökelmiştir. Gözeneklilik-geçirimlilik analizlerine göre birim \%30 ile \%45 arasında gözeneklilik, 5.2 ve $7.7 \mathrm{md}$ arasında değişen geçirimlilik değerlerine sahiptir. Formasyonun; tabakalı, bol çatlaklı ve erime boşluklu olması birimde iyi bir gözeneklilik oluşturmuştur. Ancak, gözenekliliği büyük ölçüde artıran formasyondaki kırık ve çatlakların ikincil kalsit, demirli (Fe) ve manganlı (Mn) çimento ile dolması nedeniyle geçirgenlik değerleri gözeneklilik kadar yüksek değildir. Sonuç olarak, arazi ve laboratuvar çalışmalarına göre Mollaresul formasyonu orta dereceli hazne kaya niteliği göstermektedir.

Anahtar Kelimeler: Haymana, kireçtaşı, Mollaresul, petrol, rezervuar

Abstract: Detailed research on the quality of the reservoir for oil research and production is very important to reduce costs because of the high cost of oil exploration and evaluation. The aim of this study is to determine petroleum reservoir rock quality of the Mollaresul formation which is composed of Jurassic-Lower Cretaceous aged limestones within the Haymana-Polatl basin. The reservoir quality of the limestones was determined by standard field studies and laboratory analyzes, porosity-permeability analyzes and petrographic studies. In the field studies, the formation is observed as massive and stratified, and it is deposited from a shallow to deeper marine environment. According to porosity-permeability analyses, the porosity values of the formation are between $30 \%$ and $45 \%$, and the permeability values are between 5.2 and $7.7 \mathrm{md}$. Layered, abundant cracked and karstic cavities of the formation formed a good porosity in the formation. Although fractures and cracks in the formation greatly increased porosity, secondary calcite, ferrous $(\mathrm{Fe})$ and manganese ( $\mathrm{Mn}$ ) cement filling the fractures and cracks did not make the permeability as high as the porosity. In conclusion, according to the field and laboratory studies, Mollaresul formation shows a moderate reservoir rock quality.

Keywords: Haymana, limestone, Mollaresul, petroleum, reservoir

*Yazışma / Correspondence: ozdemir.ayfer@gmail.com

(C) 2019 JMO Her hakkı saklıdır/All rights reserved http://tjb.jmo.org.tr http://dergipark.gov.tr/tjb 


\section{GíRIŞ}

Çalışma alanı, Haymana-Polatlı havzası içinde Yenimehmetli ve İkizce mahalleri arasında Çayraz köyünün güneyi ile Haymana ilçesi arasında yer almaktadır (Şekil 1). Haymana-Polatlı havzasında mostra veren bitümlü kumtaşları pek çok araştırmacı tarafından stratigrafik ve sedimantolojik olarak incelenerek, havza evrimini anlamak ve petrol potansiyelini ortaya koymak amaçlı araştırma ve incelemelerde bulunulmuştur (Rigo de Righi ve Cortesini, 1960; Turkish Gulf Oil, 1961; Yüksel, 1970; Akarsu, 1971; Norman, 1972; Uğurtaş, 1975; Arıkan, 1975; Sirel, 1975; Gökçen, 1976; Ünalan vd., 1976; Turgut, 1978; Görür ve Derman, 1978; Derman, 1980; Toker, 1979 a,b; Görür, 1981; Şengör ve Y1lmaz, 1981; Ünalan ve Yüksel, 1985; Capraru, 1991; Demirel ve Şahbaz, 1994; Sonel vd., 1996; Ayyıldız ve Sonel, 2000; Aydemir, 2011; Ayyıldız ve Ergene, 2016; Okay ve Altınel, 2016). Haymana-Tuzgölü ve Bala yörelerinde Üst Kretase-Eosen yaş aralığında yaklaşık 10000 metre kalınlığındaki birimler Haymana, algli kireçtaşı, Küredağ, Çayraz ve Bala formasyonları adı altında Arıkan (1975) tarafından incelenmiştir. Bu çalışmada, Üst Kretase ve daha yaşlı birimler ana kaya, Paleosen karbonatları ile Eosen ve Oligosen kumtaşları ise hazne kaya olarak yorumlanmıştır. Sonel vd. (1996) tarafindan Tuzgölü Havzası'nda petrol arama amaçlı yapılan çalışmada Haymana, Bala ve Tuzgölü bölgeleri olarak değerlendirilen havzaların bir olduğu ileri sürülmüş ve her üç bölgede yüzeyleyen birimlerde karşılaştırma ve değerlendirme yeniden yapılmıştır. Havza Haymana-Polatlı, Bala-Kırıkkale, Ş.KoçhisarAksaray olarak alt bölümlere ayrılarak incelenmiştir. Söz konusu çalışmada; HaymanaPolatlı bölgesinde yaşlidan gence doğru Haymana, Kartal, Çaldă̆, Kırkkavak, Eskipolatlı, Çayraz ve Cihanbeyli formasyonlarının bulunduğu belirtilmiştir. Kırkkavak ve Kartal formasyonlarının şeyl birimlerinin petrol kaynak kaya (Ayyıldız ve Sonel, 2000), Eskipolatlı ve
Haymana formasyonlarının türbiditik kumtaşları ise petrol hazne kaya özelliğindedir (Görür ve Derman, 1978). Haymana ve Karapınar yaylası formasyonları hazne ve kaynak kaya özellikleri göstermesine rağmen Çaldağ formasyonu hazne kaya olarak önem arz etmemektedir (Sonel vd., 1999; Ayyıldız ve Ergene, 2016). Tuz Gölü Havzası Kuzeyi’nde Haymana Formasyonu'nun organik madde miktarının Haymana-Polatlı bölgelerinde KKD'dan GGB'ya doğru azaldığı, Bala-Kırıkkale arasında ise KKD'dan GGB'ya doğru arttığ1, organik madde türünün hemen hemen her yerde Tip III kerojenden oluştuğu, olgunlaşmanın petrol-erken gaz zonunda olduğ Acar (2000) tarafından belirtilmiştir. Haymana Polatlı havzasında en aktif volkanik faaliyetler Neojen döneminde gelişmiştir. Bölge tektonik yapısını sıkışma rejimi altında kazanmıştır. Bunun sonucunda bölgede hakim olarak kıvrımlar, normal faylar ve ters faylar (bindirmeler ve büyük açılı ters faylar) gelişmiştir (Sonel vd., 1996). İnceleme alanındaki ters fay Dereköy bindirmesidir. Çalışma alanındaki antiklinal Haymana antiklinalidir

$\mathrm{Bu}$ çalışmada, Türkiye'deki petrol arama ve geliştirme çalışmalarına katkıda bulunmak amaciyla, Haymana-Polatlı havzasinda yer alan, Haymana yakın civarında yüzlek veren Jura-Alt Kretase yaşlı Mollaresul formasyonu kireçtaşlarının petrol hazne kaya özellikleri gözeneklilik-geçirimlilik analizleri ve petrografik incelemelerle ortaya konulmuştur.

\section{MATERYAL VE YÖNTEM}

Jura-Alt Kretase yaşlı kireçtaşlarının rezervuar kalitesini belirlemek için standart saha ve laboratuvartekniklerikullanılmıştır.Kireçtaşlarının sedimantolojik özelliklerini tanımlamak için araziden alınan ondört adet el örneğinden ince kesit yapılarak optik mikroskopta petrografik analizler (tane durumu, fosil içeriği, fosil oranı, tane bileşimi ve doku) yapılmıştır. Örnekler, Folk (1959) ve Dunham (1962) siniflandirmalarına 
göre tanımlanmıştır. Porozimetre (Hellium gazı genleşme porozimetresi) ve permeametre (Temco $\mathrm{RCH}$ serisi model) kullanılarak gözeneklilik ve geçirgenlik onbir adet örnek üzerinde ölçülmüştür. $\mathrm{Bu}$ analizler tapalar üzerinde yapılmıştır. Tapaların standart ölçüleri $2.5 \mathrm{~cm}$ çapında ve $5-6 \mathrm{~cm}$ uzunluğunda olup, rezervuar kaya analizleri Orta Doğu Teknik Üniversitesi Petrol Mühendisliği laboratuvarında, petrografik incelemeler Ankara Üniversitesi Mühendislik Fakültesi Jeoloji Mühendisliği Bölümü laboratuvarında yapılmıştır.

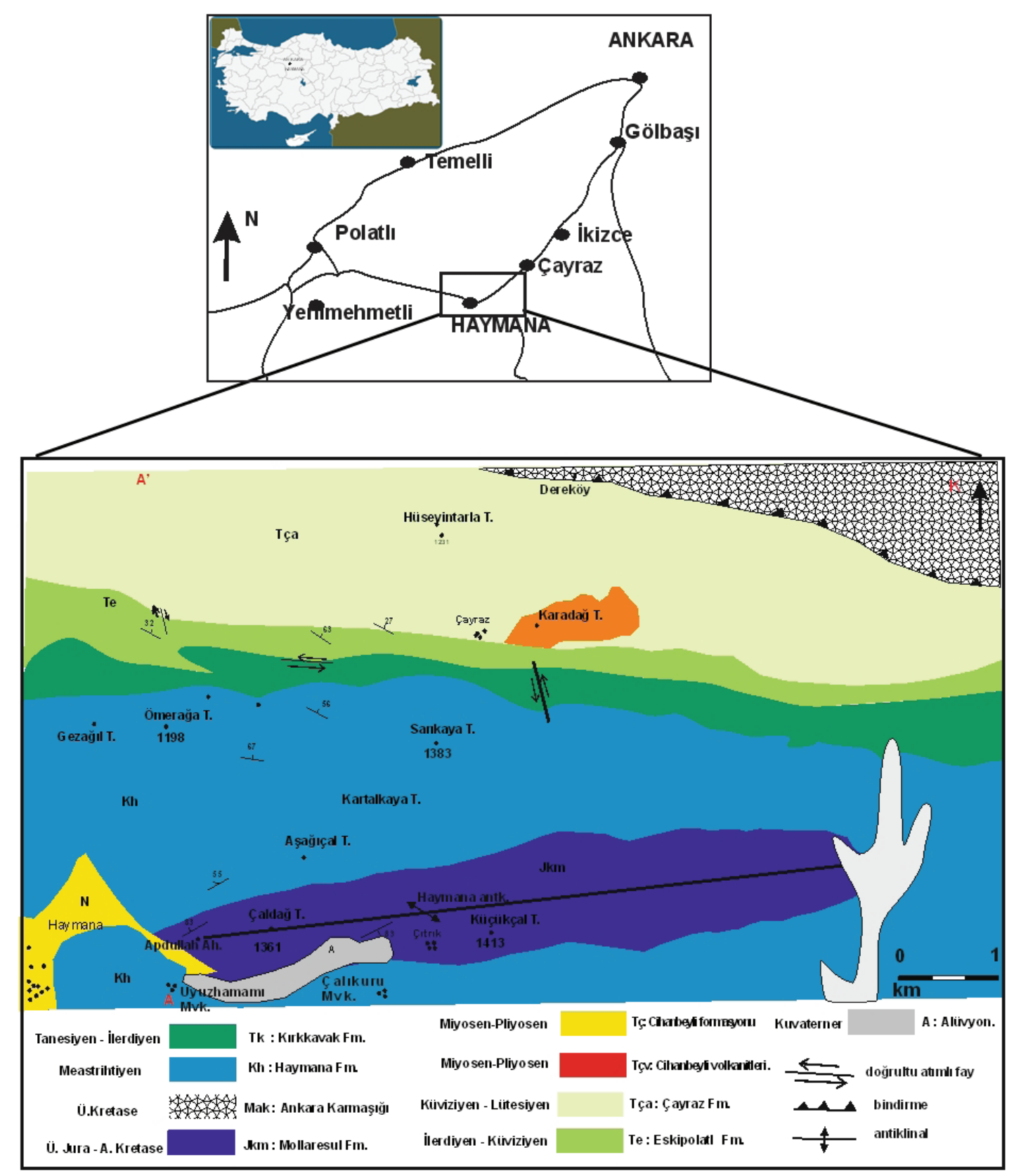

Şekil 1. İnceleme alanı yer bulduru ve jeoloji haritası (Sonel ve diğ., 1996)

Figure 1. Location and geological map of the study area (Sonel et al., 1996) 


\section{MOLLARESUL FORMASYONU'NUN JEOLOJISİ}

Çalışma alanında Jura-Alt Kretase yaşlı Mollaresul formasyonu en yaşlı birimdir. Üst Kretase yaşlı Ankara Karmaşığı birimin üzerinde tektonik dokanakla yer almaktadır. Ankara karmaşığının içinde Permo-Karbonifer-Kretase yaşlı kireçtaş1 blokları, Triyas yaşlı metagrovaklar, volkanik kayaçlar ve ofiyolitik karmaşığa ait birimler bulunmaktadır. Temel birimleri üzerine Geç Kampaniyen-Eosen yaşlı ve sürekli bir istif sunan sedimanter birimler gelmektedir. $\mathrm{Bu}$ birimler Haymana (Geç Kampaniyen-Maastrihtiyen), Kartal (Paleosen-Orta Eosen), Çaldağ (Paleosen), Kirkkavak (Paleosen), Eskipolatlı (Eosen) ve Çayraz (Orta Eosen) formasyonlarıdır. Üst Kretase-Eosen zaman aralığında denizin havzadaki transgresif ve regresif özeliklerine bağl1 olarak birimlerde yanal ve düşey yönde litofasiyes değişiklikleri gözlenir. Ayrıca, bu zaman aralığında havzanın derin kısımlarında filiş karakterli birimler çökelirken kenar kısımlarında ise karasal ve sı̆̆ denizel birimlerin çökeldiği, birbirleriyle yanal ve düşey yönde ilişkide bulundukları gözlenmiştir. Bu birimlerin üzerine açısal uyumsuz olarak Miyo-Pliyosen yaşlı Cihanbeyli formasyonu gelmektedir (Sonel vd., 1996) (Şekil 2).
Kireçtaşlarından oluşan Mollaresul formasyonu ilk olarak Ünalan (1976) tarafindan adlandırılmıştır. Daha önce aynı sahada çalışanlardan Yüksel (1970) ve Sirel (1975) aynı formasyonu Çaldağ formasyonu, Akarsu (1971) ise Çengeldağ formasyonu adı altında incelemişlerdir. Birim çalışma alanında Mollaresul yaylası dolaylarında Haymana yakın doğusunda Haymana antiklinalinin çekirdeğinde yüzlek vermektedir (Şekil 1). Mollaresul formasyonun kalınlığ1 Dellaloğlu'na (1991) göre 250-300 m, Ünalan ve Yüksel (1985)'e göre de 420 m'dir. Tamamen kireçtaşlarından oluşan bu formasyon yer yer tabakalı, yer yer de masif ve tabakasızdır. Birimin tabakalı olduğu yerler, Çıtrık ve Apdullah ahılı mevkileridir. Kireçtaşları bu mevkilerde açık sarı renkli, oldukça kırılgan çatlaklar arası kalsit, mangan ve demir çimentolu, tabaka kalınlıkları 5 $\mathrm{cm}$ ile 30-40 $\mathrm{cm}$ arasında değişmektedir. Tabaka eğimleri $55 \mathrm{~GB}$ ve $85 \mathrm{~GB}$ arasında değişmektedir (Şekil 3). Formasyonunun masif k1sımları; Çaldağ tepe ile Küçükçal tepe ve civarında gözlenmektedir. Grimsi beyaz ve sarı renkli olup çört yumruludur. Bol erime boşluklu, çatlaklı ve çatlaklar arası ikincil kalsit çimento dolguludur. Masif kesimleri bol çatlaklı ve erime boşlukludur. Erime boşlukları yüksek derecede gözeneklilik oluşturur (Şekil 4). Kireçtaşlarının bol çatlaklı olması, gözenekliliği ve geçirimliliği artırması açısından umut vericidir. 


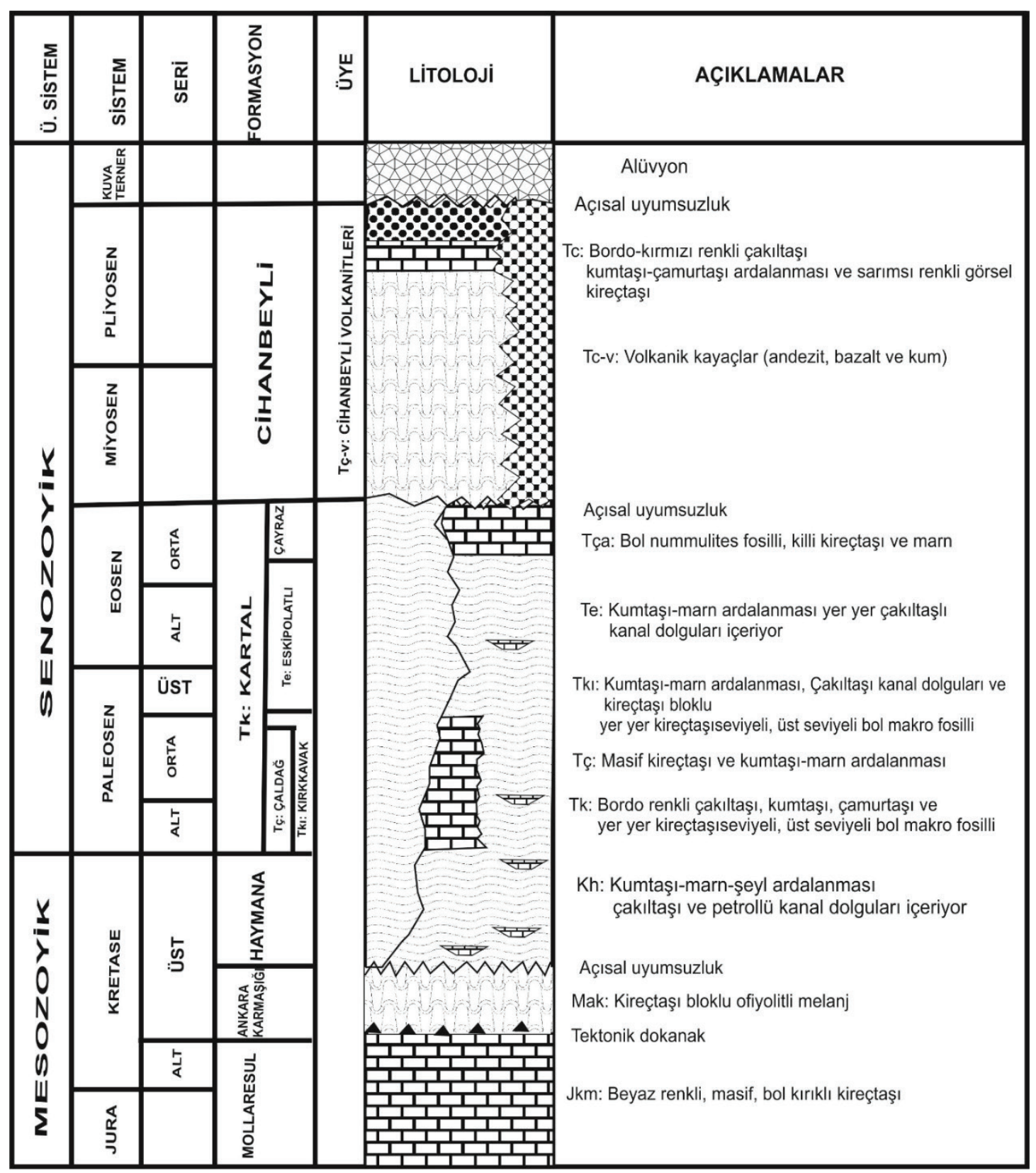

Şekil 2. Haymana-Polatlı havzasının genelleştirilmiş stratigrafik sütün kesiti (Sonel vd., 1996)

Figure 2. Generalized column section of Haymana-Polatl basin (Sonel et. al., 1996) 


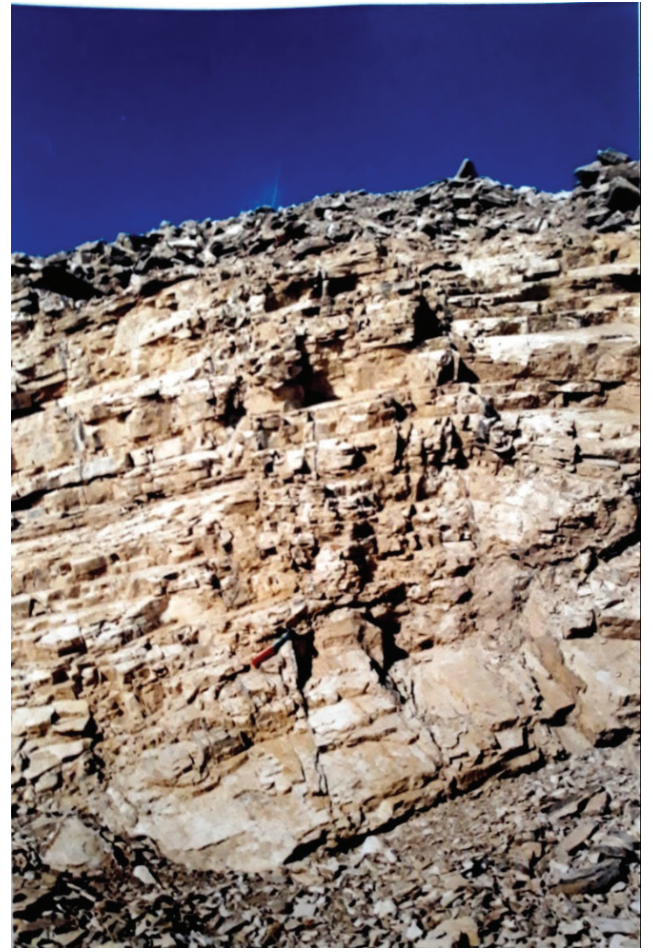

Şekil 3. Mollaresul formasyonu kireçtaşlarının tabakalı kısmının uzaktan görünümü, birim ince- orta katmanlı olup GB'ya eğimlidir.

Figure 3. Remote view of the layered part of the limestones of Mollaresul formation, they are thin to medium bedded and dip to SW.

Çalışma alanında Haymana formasyonu örtü kaya olarak Mollaresul formasyonunu üzerine gelmektedir. Gönenç (1978)'e göre; Yenimehmetli' de yüzeyleyen Üst Jura-Alt Kretase yaşlı kireçtaşlarının Mollaresul formasyonu olarak kabul edilse de, bunların ofiyolitik melanjla birlikte gelen allokton blok olma olasılığı vardır.
Yıldız dağ1 güneyinde aynı nitelikteki kireçtaşları Ankara karmaşığ1 içinde küçük bloklar halinde gözlendiği için birim alloktondur. Birimin Apdullah ahılı mevkiinde yeni yol üzerinde ortaya çıkan mostrasına göre formasyonun tabaka kalınlıkları $30 \mathrm{~cm}$ 'den $10 \mathrm{~cm}$ 'ye değişerek Haymana formasyonuna dereceli geçişli dokanak yapmaktadır. Haymana ve Mollaresul formasyonu birlikte monoklinal kıvrımlanmaya uğramıştır (Şekil 5). Bu nedenlerle, formasyon inceleme alanında otoktondur.

Mollaresul Formasyonu'na Ünalan (1976) Üst Kretase-Alt Kretase, Dinçer (1978) Üst JuraÜst Kretase (Türoniyen) ve Toker (1979) Üst Jura-Alt Kretase yaşını vermişlerdir. Mollaresul formasyonununyaşıylailgiliyukarıda dabelirtildiği gibi tam bir kesinlik yoktur. Ancak, formasyonda tespit edilen Globigerina sp., Marginotruncano sp. fosilleri Turoniyen-Santoniyen yaş aralığını vermektedir (Şekil 6a) Formasyondaki Radiolaria sp.ve sünger spiküllerinin artması birimin sı̆̆ denizel ortamdan daha derinleşen bir ortama doğru çökelimin olduğuna işaret etmektedir (Şekil 6b). Rotalipora sp., Trocholina sp. fosilleri Alt Kretase'yi ve derinleşen deniz ortamında çökelimi belirtmekte olup (Şekil 6c), birim içindeki tabakalı kireçtaşlarından alınan örneklerde bulunan Marginotruncano sp. Radiolaria sp ve sünger spikülleri; tabakalı kireçtaşlarının derin deniz ortamında Üst Kretase'de oluştuğunu yansıtmaktadır. Bu bulgular çevresinde inceleme alanında jeolojik haritada verilen A-A' hattı boyunca genelleştirilmiş stratigrafik kolon kesit Şekil 7'de gösterilmektedir. 


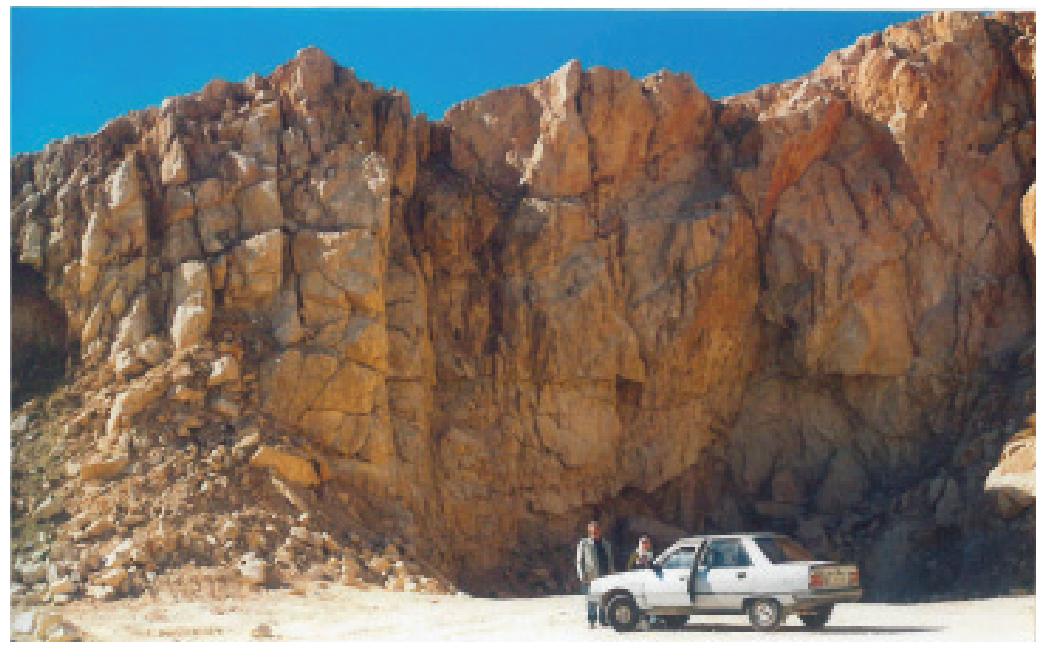

Şekil 4. Mollaresul formasyonunun masif kireçtaşlarındaki erime boşlukları

Figure 4. Karstic cavities in the massive limestones of Mollaresul Formation

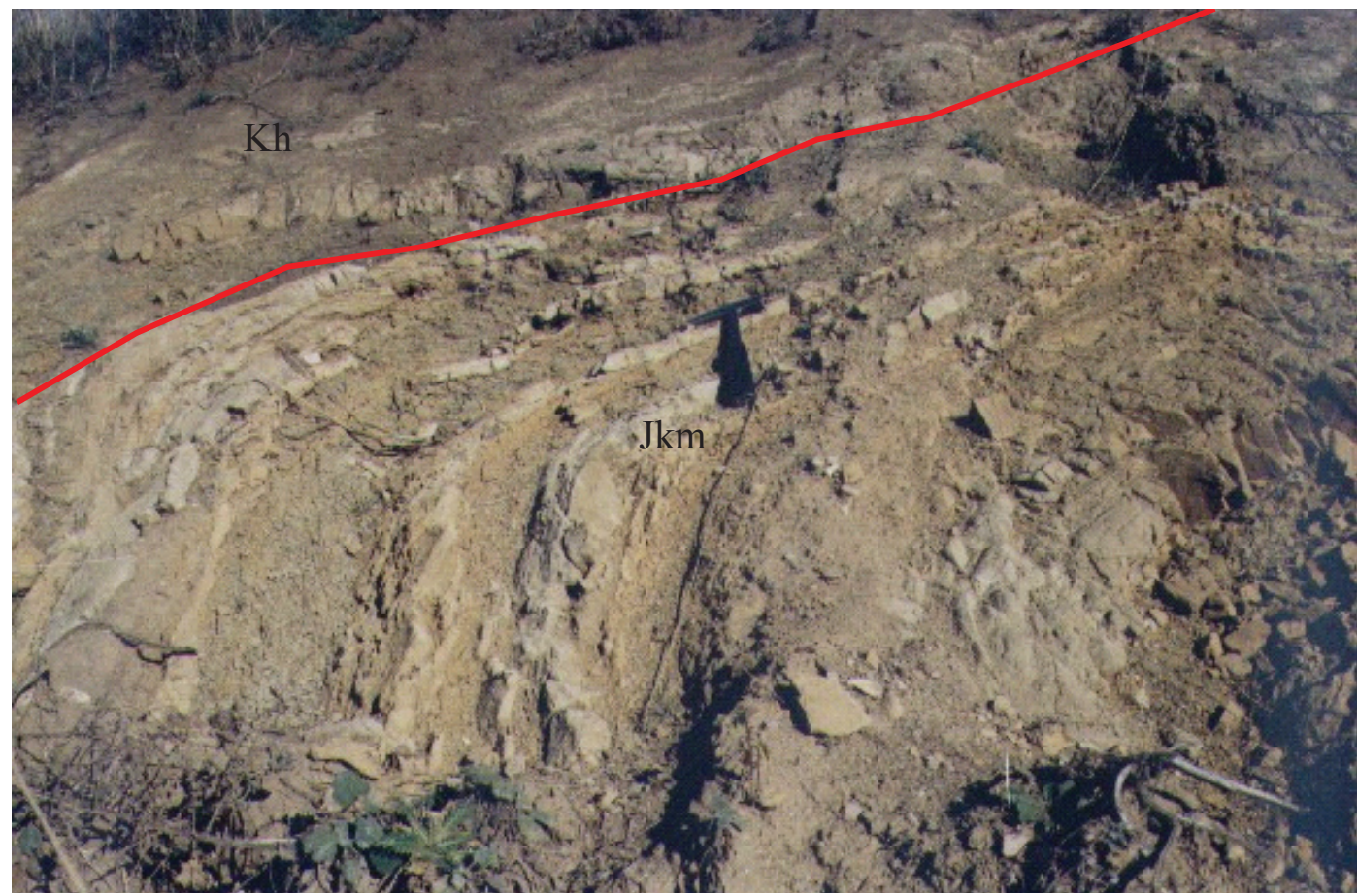

Şekil 5. Mollaresul formasyonuyla Haymana formasyonu arasındaki dereceli geçişli dokanak. Her iki birim birlikte monoklinal kıvrımlanmaya uğramıştır. (Apdullah ahılı civarında Gölbaşı-Haymana arasında yeni yol üzeri)

Figure 5. Gradual transition between Mollaresul formation and Haymana formations, and a local monocline which affected both formations. (near Abdullah Ahıl on the new roads between Gölbaş1-Haymana) 

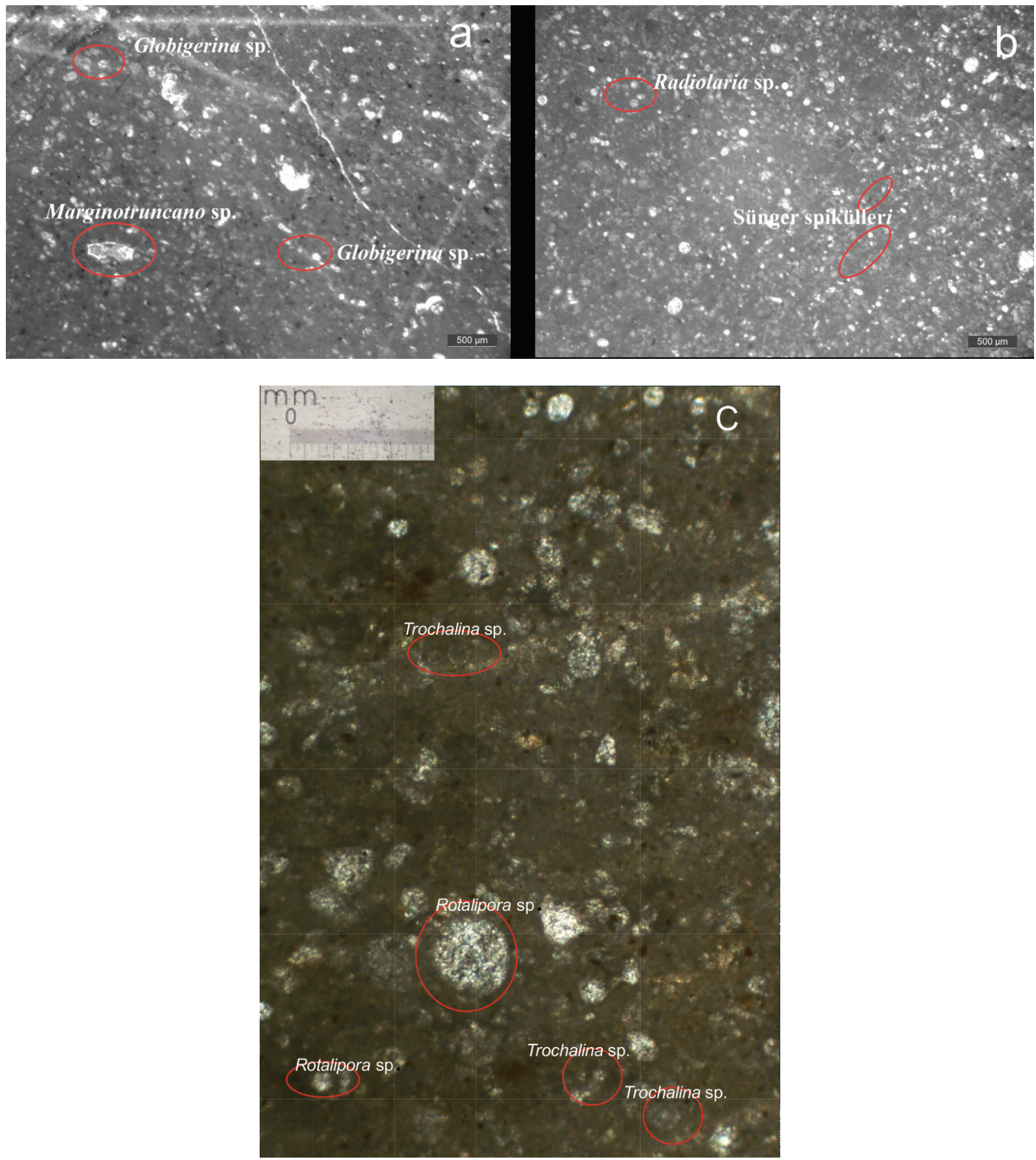

Şekil 6. a. Turoniyen-Santoniyen yaş aralığını temsil eden Globigerina sp., Marginotruncano sp. b. Derin deniz ortamını temsil eden Radiolaria sp. ve sünger spikülleri c. Alt Kretase'yi ve derinleşen deniz ortamında çökelimi belirten Rotalipora sp., Trocholina sp. fosilleri

Figure 6. a. Globigerina sp. and Marginotruncano sp. fossils representing the Turonian-Santonian age b. Radiolaria $s p$. and sponge spicules representing deepening environment c. Rotalipora sp. and Trocholina sp. fossils representing the Lower Cretaceous and deepening marine environment 


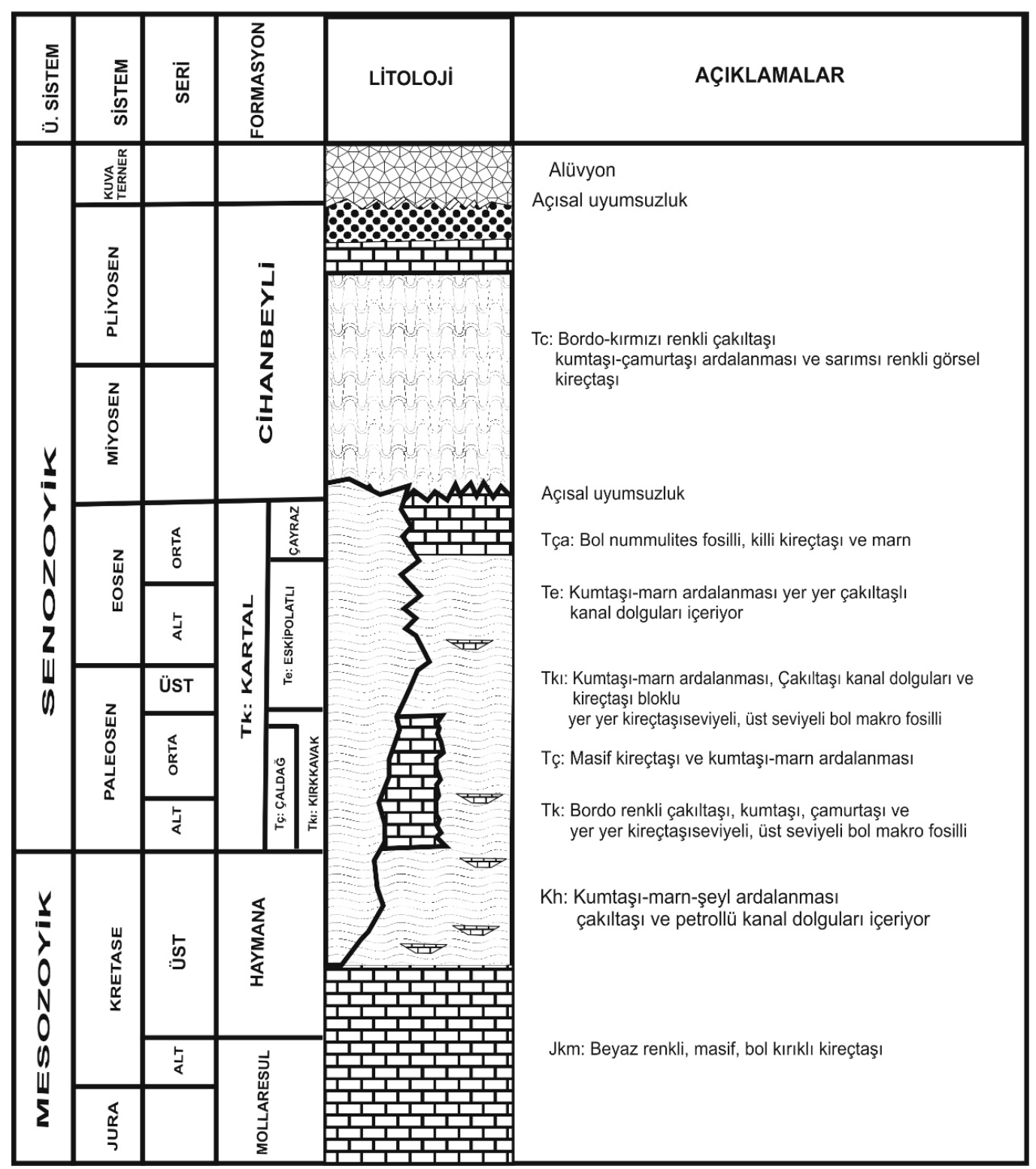

Şekil 7. Çalışma Alanının genelleştirilmiş stratigrafik sütün kesiti (A-A' Apdullah Ahılı)

Figure 7. Generalized column section of the study area (A-A'Apdullah Ahill)

\section{PETROGRAFÍK İNCELEMELER}

Mollaresul formasyonunun arazi gözlemlerinden sonra hazne kaya özelliklerini araştırmak için araziden toplanan ondört adet kireçtaş1 numunesinden ince kesitler oluşturarak petrografik incelemeler yapılmıştır. Örneklerin tane durumu, taneler arasındaki çimento durumu (Çizelge
1), dokusu, fosil tipleri ve bu fosil tiplerinin oranları belirlenerek Folk (1959) ve Dunham (1962)'ye göre kireçtaşı örnekleri (Çizelge 2, 3) sınıflandırılmıştır. Formasyonunun tabakalı olan kısımları hazne kaya özelliği taşır. Kireçtaşları çatlaklı olup, petrografik incelemeler çatlakların ikincil kalsit, demir $(\mathrm{Fe})$ ve mangan $(\mathrm{Mn})$ çimento dolgulu olduğunu göstermektedir. 
Çizelge1. Mollaresul formasyonu kireçtaşı örneklerinin çimento tipi

Table 1. Cement type of Mollaresul formation limestone samples

\begin{tabular}{|c|l|}
\hline Örnek no & \multicolumn{1}{c|}{ Çimento } \\
\hline 1 & Tane destekli, İkincil kalsit ve Fe dolgu \\
\hline 2 & Tane destekli, İkincil kalsit ve Fe dolgu \\
\hline 3 & Tane destekli, İkincil kalsit ve Fe dolgu \\
\hline 4 & Tane destekli, İkincil kalsit ve Fe dolgu \\
\hline 5 & Matriks biraz daha fazla, İkincil kalsit ve Fe dolgu \\
\hline 6 & Matriks biraz daha fazla, İkincil kalsit ve Fe dolgu \\
\hline 7 & Tane destekli, İkincil kalsit ve Fe dolgu \\
\hline 8 & Tane destekli, İkincil kalsit ve Fe dolgu, Fe oranı fazla \\
\hline 9 & Tane destekli, İkincil kalsit ve Fe dolgu \\
\hline 10 & Tane destekli, İkincil kalsit ve Fe dolgu \\
\hline 11 & Tane destekli, İkincil kalsit ve Fe dolgu \\
\hline 12 & Tane destekli, İkincil kalsit ve Fe dolgu \\
\hline 13 & Tane destekli, İkincil kalsit ve Fe dolgu \\
\hline 14 & Tane destekli, İkincil kalsit ve Fe dolgu \\
\hline
\end{tabular}

Kireçtaşları Echinid, Alg, Brachiopod, Gastropod kavkıları,Trocholina sp., Rotalipora sp., Radiolaria sp. , Globigerina sp., Marginotruncano sp., Sünger spikülü ve Foraminifer fosilleri içermektedir. Kireçtaş1 örnekleri $\% 60-80$ oranında intraklast, $\% 10$ ooid,
\%3-15 Foraminifer, \%5 Brachiopod kavk1, \%2-10 pizoid, \%10-25 Echinid,, \%15-20 Trocholina sp., \%10-15 Rotalipora sp., \%10-15 Radiolaria sp., \%5 Alg, \%5 Sünger spikülü, \%2-5 Gastropod kavk1, \%2-5 Globigerina sp. ve \%2-5 Marginotruncano sp. içermektedir (Tablo 2). 
Çizelge 2. Mollaresul formasyonu kireçtaşı örneklerinin fosil içeriği ve oranları

Table 2. Fossil content and proportions of Mollaresul formation limestone samples

\begin{tabular}{|c|c|c|c|}
\hline Örnek no & $\begin{array}{l}\text { Fosil } \\
\text { Oranı }\end{array}$ & Fosil İçeriği & Tane Bileşimi (\%) \\
\hline 1 & $\% 35$ & $\begin{array}{l}\text { Echinid, Alg, Brachiopod } \\
\text { kavk1, Foraminifer }\end{array}$ & $\begin{array}{l}\text { İntraklast } \% 60 \text {, Foraminifer } \% 15 \text {, Brachiopod kavk1 } \\
\% 5 \text {, Echinid } \% 10 \text {, Alg } \% 5 \text {, pizoid } \% 5\end{array}$ \\
\hline 2 & $\% 20$ & Echinid & İntraklast $\% 70$, Echinid $\% 20$, Ooid $\% 10$ \\
\hline 3 & $\% 35$ & $\begin{array}{l}\text { Echinid, Brachiopod } \\
\text { kavk1, Gastropod, } \\
\text { Foraminifer } \\
\end{array}$ & $\begin{array}{l}\text { İntraklast } \% 65 \text {, Echinid } \% 15 \text {, Gastropod } \% 5 \text {, } \\
\text { Brachiopod kavk1 } \% 5 \text {, Foraminifer } \% 10\end{array}$ \\
\hline 4 & $\% 25$ & Echinid & İntraklast- $\% 75$, Echinid- $\% 25$ \\
\hline 5 & $\% 30$ & $\begin{array}{l}\text { Trocholina sp., Rotalipora } \\
\text { sp. }\end{array}$ & $\begin{array}{l}\text { İntraklast-\%70, Trocholina sp. \%20, Rotalipora sp. } \\
\% 10\end{array}$ \\
\hline 6 & $\% 30$ & $\begin{array}{l}\text { Trocholina sp., Rotalipora } \\
\text { sp. }\end{array}$ & $\begin{array}{l}\text { İntraklast } \% 70, \text { Trocholina sp. } \% 15, \text { Rotalipora } \mathrm{sp} . \\
\% 15\end{array}$ \\
\hline 7 & $\% 30$ & $\begin{array}{l}\text { Radiolaria } \text { sp., Rotalipora } \\
\text { sp.,, Sünger spikülü, }\end{array}$ & $\begin{array}{l}\text { İntraklast-\%70, Radiolaria sp. } \% 15, \text { Rotalipora } \mathrm{sp.} \\
\% 10, \text { Sünger spikülü } \% 5\end{array}$ \\
\hline 8 & $\% 25$ & $\begin{array}{l}\text { Echinid, Foraminifer, } \\
\text { Gastropod }\end{array}$ & $\begin{array}{l}\text { İntraklast } \% 80 \text {, Foraminifer } \% 5 \text {, Echinid } \% 5 \text {, } \\
\text { Gastropod } \% 2 \text {, pizoid } \% 2\end{array}$ \\
\hline 9 & $\% 15$ & $\begin{array}{l}\text { Globigerina sp., } \\
\text { Marginotruncano sp., } \\
\text { Radiolaria sp. }\end{array}$ & $\begin{array}{l}\text { İntraklast } \% 80, \text { Radiolaria sp. } \% 10, \text { Globigerina sp., } \\
\% 5, \text { Marginotruncano sp. } \% 5\end{array}$ \\
\hline 10 & $\% 15$ & Echinid, Foraminifer & İntraklast $\% 85$, Echinid- $\% 9$, Foraminifer $\% 6$ \\
\hline 11 & $\% 20$ & Gastropod, Foraminifer & $\begin{array}{l}\text { İntraklast } \% 80, \text { pizoid } \% 10, \text { Foraminifer } \% 7 \text {, } \\
\text { Gastropod } \% 3\end{array}$ \\
\hline 12 & $\% 15$ & $\begin{array}{l}\text { Echinid, Foraminifer, } \\
\text { Gastropod }\end{array}$ & $\begin{array}{l}\text { İntraklast } \% 85 \text {, Echinid- } \% 10 \text {, Foraminifer } \% 3 \text {, } \\
\text { Gastropod } \% 2\end{array}$ \\
\hline 13 & $\% 15$ & $\begin{array}{l}\text { Echinid, Foraminifer, } \\
\text { Gastropod }\end{array}$ & $\begin{array}{l}\text { İntraklast } \% 85 \text {, Echinid } \% 10, \text { Foraminifer } \% 3 \text {, } \\
\text { Gastropod } \% 2\end{array}$ \\
\hline 14 & $\% 20$ & Foraminifer, Gastropod & $\begin{array}{l}\text { İntraklast } 80 \text {, Foraminifer } \% 7 \text {, Gastropod } \% 3 \text {, pizoid } \\
\% 10\end{array}$ \\
\hline
\end{tabular}

Sparitik ve mikritik doku, bol çatlaklı ve ortalama \%23 oranında fosil içeriğine sahip kireçtaş1 örnekleri Folk (1959)'a göre kötü yıkanmış biyosparit, Dunham (1962)'a göre ise İstif taşı olarak tanımlanmaktadır. Mikrit dokulu ortalama \%26 fosil içeriğine sahip kireçtaşları Folk (1959)'a göre seyrek paketlenmiş biyomikrit, Dunham (1962) referans alındığında ise vake taşı olarak adlandırılmıştır. 
Çizelge 3. Dunham (1962) ve Folk (1959)'a göre Mollaresul formasyonunun karbonat kaya sinıflandırması

Table 3. Carbonate rock classification of Mollaresul formation according to Dunham (1962) and Folk (1959)

\begin{tabular}{|c|l|c|l|}
\hline Örnek no & \multicolumn{1}{|c|}{ Dokusu } & Dunham (1962) & \multicolumn{1}{c|}{ Folk (1959) } \\
\hline 1 & Sparitik ve mikritik doku, bol çatlaklı & İstif taşı & Kötü yıkanmış biyosparit \\
\hline 2 & Sparitik ve mikritik doku, bol çatlaklı & İstif taşı & Kötü yıkanmış biyosparit \\
\hline 3 & Sparitik ve mikritik doku, bol çatlaklı & İstif taşı & Kötü yıkanmış biyosparit \\
\hline 4 & Sparitik ve mikritik doku, bol çatlaklı & İstif taş1 & Kötü yıkanmış biyosparit \\
\hline 5 & Mikritik doku, bol çatlaklı & Vake taş1 & Seyrek paketlenmiş biyomikrit \\
\hline 6 & Mikritik doku, bol çatlaklı & Vake taşı & Seyrek paketlenmiş biyomikrit \\
\hline 7 & Mikritik doku, bol çatlaklı & Vake taşı & Seyrek paketlenmiş biyomikrit \\
\hline 8 & Mikritik doku, bol çatlaklı & Vake taş1 & Seyrek paketlenmiş biyomikrit \\
\hline 9 & Fe oranı fazla, mikritik doku & Vake taşı & Seyrek paketlenmiş biyomikrit \\
\hline 10 & Fe oranı fazla, sparitik ve mikritik doku & İstif taşı & Kötü yıkanmış biyosparit \\
\hline 11 & Fe oranı fazla, sparitik ve mikritik doku & İstif taş1 & Kötü yıkanmış biyosparit \\
\hline 12 & Fe oranı fazla, sparitik ve mikritik doku & İstif taşı & Kötü yıkanmış biyosparit \\
\hline 13 & Fe oranı fazla, sparitik ve mikritik doku & İstif taşı & Kötü yıkanmış biyosparit \\
\hline 14 & Fe oranı fazla, sparitik ve mikritik doku & İstif taşı & Kötü yıkanmış biyosparit \\
\hline
\end{tabular}

\section{GöZENEKLİLIKK- GEÇiRIMLİLİK} ANALIZLLRI

Kireçtaşlarının gözeneklilik-geçirgenlik tayinlerine göre birimin gözeneklilik değerleri,

$\% 30$ ile $\% 45$ arasında, geçirgenlik değerleri ise 5,2 md ile 7,7 md arasında değişmektedir (Çizelge-4).

Kireçtaşı örneklerinin gözeneklilik ve geçirimlilik değerleri incelendiğinde 4 ve 3 numaralı örneklerin geçirimlilik değerlerinin diğer örneklere nazaran yüksek olduğu gözlenmektedir (Şekil 8).

Formasyonda yüksek gözeneklilik değerlerine karşın geçirimliliğin bu oranda yüksek olmaması geçirimliliği azaltıcı etmenler olduğunu gösterir ki bunlar, çatlakların ve tabakaların arasının ikincil kalsit $\left(\mathrm{CaCO}_{3}\right)$, demir $(\mathrm{Fe})$ ve mangan $(\mathrm{Mn})$ çimento ile dolmasıdır (Şekil 9). 
Çizelge 4. Mollaresul Formasyonu'nun gözeneklilik ve geçirimlilik değerleri

Table 4. The porosity and permeability values of Mollaresul formation

\begin{tabular}{|c|c|c|}
\hline Örnek & Gözeneklilik \% & Geçirimlilik(md) \\
\hline 1 & 35 & 6.59 \\
\hline 2 & 37 & 6.24 \\
\hline 3 & 30.3 & 7.62 \\
\hline 4 & 30 & 7.7 \\
\hline 5 & 35 & 6.6 \\
\hline 6 & 40 & 5.77 \\
\hline 7 & 42 & 5.8 \\
\hline 8 & 45 & 5.14 \\
\hline 9 & 45 & 5.76 \\
\hline 10 & 40 & 5.8 \\
\hline 11 & 48 & 5.2 \\
\hline
\end{tabular}

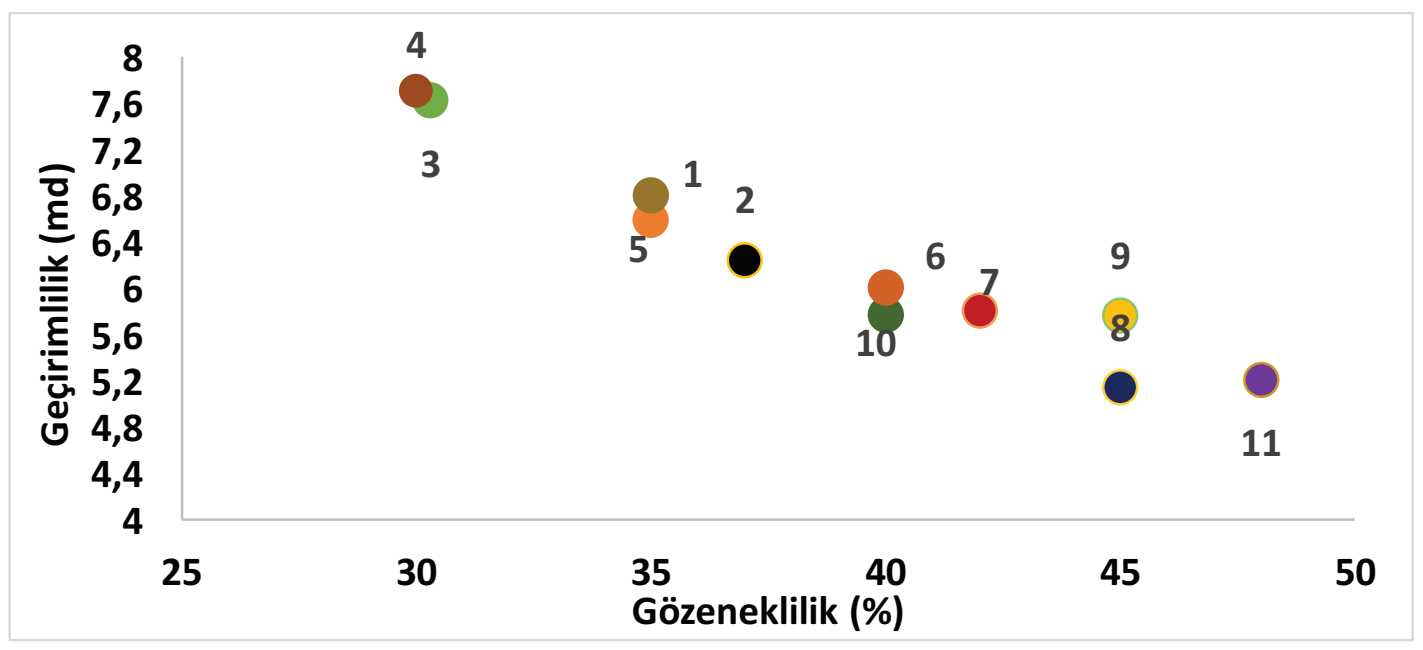

Şekil 8. Mollaresul formasyonunun Gözeneklilik ve geçirimlilik değerleri

Figure 8. The relationship between porosity and permeability of Mollaresul formation 

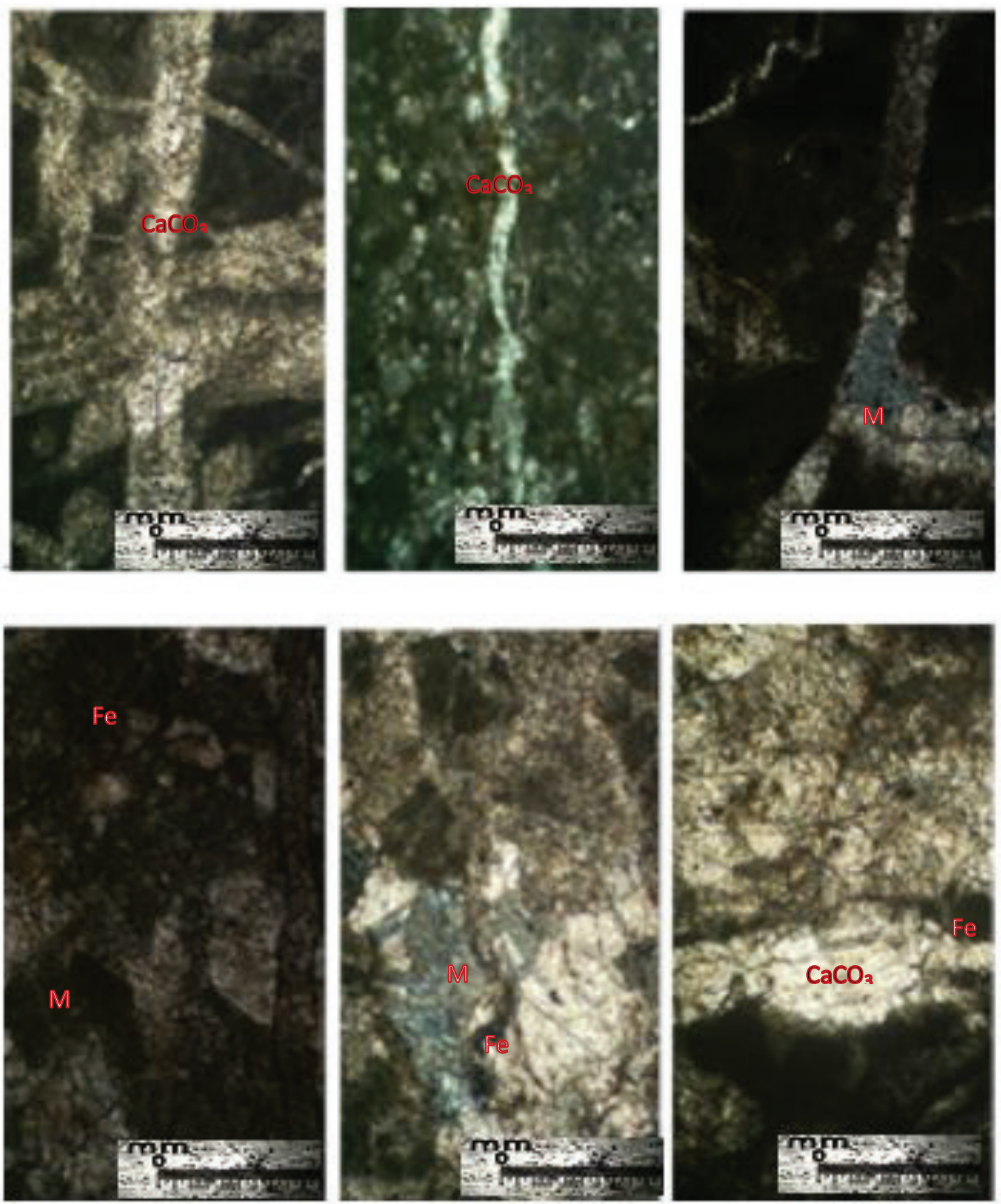

Şekil 9. Mollaresul kireçtaşı örneklerinde çatlaklar arası ikincil kalsit, Fe ve Mn çimento

Figure 9. Secondary calcite, Fe and Mn cement in between cracks of Mollaresul limestone samples 
Genel olarak, Mollaresul formasyonunun gözeneklilik değerleri \%30'dan yüksek, geçirgenliği ise 5.2-7.7 arasındadır. Formasyonunun bol çatlaklı, erime boşluklu, tabakalı litolojiye sahip olması birimde yüksek gözenekliliğe neden olmuş ancak, çatlakların ikincil kalsit, Fe ve Mn çimento ile dolması geçirimlilik değerlerinin düşük olmasına sebep olmuştur. Leverson (1967) değerlendirmesine göre Mollaresul Formasyonu orta derece hazne kaya özelliği göstermektedir.

\section{TARTIŞMA VE SONUÇLAR}

Jura-Üst Kretase yaşl1 Mollaresul Formasyonu kireçtaşlarından oluşmaktadır. Bu kireçtaşları bazı yerlerde masif bazı yerlerde ise tabakalı özellik gösteren bol erime boşluklu, yer yer çört yumrulu ve mikritik olarak gözlenir. Hem masif hem de tabakalı olduğu yerlerde bol çatlaklı özelliktedir ve çatlaklar ikincil kalsit, Fe ve Mn çimento ile doludur.

Formasyonun Apdullah ahılı mevkiinde yeni yol üzerinde ortaya çıkan mostrasına göre, Haymana formasyonuyla dereceli geçişli dokanak yapmas1, formasyonun inceleme alanında otokton olduğunu göstermektedir.

Formasyondan alınan kireçtaşı örneklerinde yapılan petrografik incelemelere göre masif kireçtaşları, Folk, (1959) kireçtaşı sınıflamasına göre, kötü boylanmış biyosparit, Dunham (1962) kireçtaşı sınıflamasına göre de istif taşıdır. Tabakalı kireçtaşları ise Folk (1959)'a göre seyrek paketlenmiş biyomikrit, Dunham (1962)'ye göre vake taşıdır.

Kireçtaşlarının içerdiği Globigerina sp. ve Marginotruncano sp. fosilleri TuroniyenSantoniyen yaş aralığını vermektedir. Formasyondaki Radiolaria sp. ve sünger spiküllerinin artması birimin, sı ̆ denizel ortamdan daha derinleşen bir ortama doğru çökelimin olduğuna işaret etmektedir. Tabakalı kireçtaşlarından alınan örneklerde bulunan Marginotruncano sp., Radiolaria sp. ve sünger spikülleri; tabakalı kireçtaşlarının derin deniz ortamında Üst Kretase'de oluştuğunu yansitmaktadir.

Gözeneklilik-geçirimlilik analizlerine göre birim \%30 ile \%45 arasında gözeneklilik, 5.2 ve 7.7 md arasında değişen geçirimlilik değerlerine sahiptir. Formasyonun; tabakalı, bol çatlaklı ve erime boşluklu olması birimde iyi bir gözeneklilik oluşturmuştur. Ancak, gözenekliliği büyük ölçüde artıran formasyondaki kırık ve çatlakların ikincil kalsit, demirli (Fe) ve manganlı ( $\mathrm{Mn})$ çimento ile dolması nedeniyle geçirgenlik değerleri gözeneklilik kadar yüksek değildir. Sonuç olarak, arazi ve laboratuvar çalışmalarına göre Mollaresul formasyonu orta dereceli hazne kaya niteliği göstermektedir.

\section{KATKI BELİRTME}

$\mathrm{Bu}$ çalışma sırasında değerli bilgileri paylaşan ve beni yönlendiren Prof. Dr. Nurettin SONEL, arazi çalışması sırasında örneklerin alınmasına, taşınmasına yardım eden rahmetli annem ve babam Ayşe ve Cemil ÖZDEMIR'e, ODTÜ Petrol Mühendisliği'nde rezervuar analizlerine yardımc1 olan Prof. Dr. Ali Suat BAĞCI ve Gürkan İŞCAN'a, fosil adlandırılmasında yardımcı olan Ercan BAYRAK, Prof. Dr. Vedia Toker'e ve Dr. Burcu TUNABOYLU'ya en derin sevgi ve saygılarımı sunarım.

\section{EXTENDED SUMMARY}

Reservoir quality is very important for oil research and production because the cost of oil exploration and evaluation is very high. Detailed information on reservoir quality is required to reduce costs. The aim of this study is to define petroleum reservoir rock quality of Mollaresul formation which is composed of the Jurassic- Lower Cretaceous aged limestones in the Haymana-Polatl basin. 
Standard field studies and laboratory analyzes were performed to determine the reservoir quality of the limestones, the reservoir quality of Mollaresul formation limestones was revealed by helping permeability-porosity analyzes and petrographic examinations.

The formation is composed entirely limestones. In some places, limestones are massive, micritic, cherty-nodular, and in some places, it consists karstic cavities in the massive units of the formation. . The limestones are filled with secondary calcite, $\mathrm{Fe}$ and $\mathrm{Mn}$ cement in cracked places. Haymana formation overlies Mollaresul formation as a cover in the study area.

According to the petrografic studies of the formation, massive limestones are poorly sorted biosparite according to Folk, (1959), limestones are called as stack stone classification with respect to Dunham (1962). However, the layered limestones are called as sparsely packed biomicrite with respect to Folk (1959).

Fossil contents of the formation represent that the stratified sections were deposited in the Upper Cretaceous in the deep-sea environment.

Field and laboratory studies show that the formation has a high degree of porosity. According to porosity-permeability analyses, the porosity values of the formation are between 30\% and $45 \%$, and the permeability values are between 5.2 and $7.7 \mathrm{md}$. Layered, abundant cracked and karstic cavities of the formation formed a good porosity in the formation. Although fractures and cracks in the formation greatly increased porosity, secondary calcite, ferrous ( $\mathrm{Fe}$ ) and manganese (Mn) cement filling the fractures and cracks did not make the permeability as high as the porosity. In conclusion, according to the field and laboratory studies, Mollaresul formation shows a moderate reservoir rock quality.

\section{ORCID}

Ayfer Özdemir (D) https://orcid.org/0000-0001-9523-6160

\section{DEĞIINILEN BELGELER}

Acar, A., ve Sonel, N., 1998. Haymana formasyonunun (Tuz Gölü Havzası kuzeyi, Orta Anadolu) organik fasiyes ve jeokimyası. Cumhuriyetin 75 . Yıldönümü Yerbilimleri ve Madencilik Kongresi Bildiri Özleri Kitabı, 127-129.

Acar, A., 1993. Haymana Formasyonunun (Tuz Gölü Havzası Kuzeyi) Organik Fasiyes ve Diyajenetik Özelliklerinin İncelenmesi. Ankara Üniv. Fen Bil. Enst., Doktora Tezi,194 sayfa.

Akarsu, İ., 1971. II. Bölge AR/TPAO/747 nolu sahanın terk raporu. Petrol İșleri Genel Müdürlüğü, Ankara 4s (yayımlanmamış).

Arıkan, Y., 1975. Tuzgölü havzasının jeolojisi ve petrol imkanları. MTA Dergisi, 85, 17-38.

Ayyıldız, T., ve Sonel, N., 2000. Kırkkavak ve Kartal formasyonları bitümlü seviyelerinin jeokimyasal değerlendirilmesi, Orta Anadolu, Türkiye. Cumhuriyetin 75. Yıldönümü Yerbilimleri ve Madencilik Kongresi Bildiriler Kitabı-I, 229 243.

Ayyıldı,, T., and Ergene, Ş.K., 2016. Facies characteristics and reservoir properties of the Paleocene carbonates (Çaldağ Formation) in the Tuz Gölü Basin, Central Anatolia, Turkey. Journal of Petroleum Science and Engineering, 142, 186198

Aydemir, A., 2011. An integrated geophysical investigation of Haymana Basin and hydrocarbon prospective Kirkkavak Formation in Central Anatolia, Turkey. Petroleum Geoscience, 17, 91100

Capraru, C., 1991. Hydrocarbon trap types in the structural units of the Tuzgolu Basin, Ozan Sungurlu Sempozyumu, Proceedings, 156-173.

Dellaloğlu, A.A., 1991. Ankara-Temelli-HaymanaKulu-Kırıkkale arasındaki alanın jeolojisi ve petrol olanakları. TPAO Rap no:3006.

Demirel, H., ve Şahbaz, A., 1994. Haymana-Paşadağ Aladağ havzalarının petrofasiyes ve provenans karakteristikleri ile petrol potansiyeli, 10. Petrol Kongresi Bildiriler Kitab1, 5-19 
Derman, A.S., 1980. Tuzgolu doğu ve kuzeyinin jeolojisi. TPAO Raporu, No. 1512, 41s (yayımlanmamış).

Dinçer, A., 1978. Haymana-Kulu yöresinin jeolojisi ve petrol olanakları. TPAO Rapor no:1314, Ankara.

Dunham, R.J., 1962. Classification of carbonate rock according to depositional texture. In: Classification of carbonate Rocks. W.G.Ham(ed.), Member of American Associated of Petro-leum Geologists., 1, 108-121.

Erentöz, C., 1975. 1/500000 ölçekli Türkiye Jeoloji haritası ve İzahnamesi. Ankara Paftası. MTA yay., Ankara.

Erentöz, C., 1963. 1/500000 ölçekli Türkiye Jeoloji Haritası, Ankara Paftası. MTA yay., Ankara.

Folk, R.L., 1959. Practical petrographic classification of limestone. Amer. Assoc. Petr. Geol. Bull., 43, 1-38.

Folk, R.L., 1966. A review of grain-size parameters. Sedimentology, 6, 73-93.

Gökçen, S.L., 1976. Haymana Güneyinin sedimantolojik incelenmesi (GB ANKARA). H.Ü., Doçentlik Tezi, 192s.

Gökçen, S.L., 1977 a. Haymana (GB ANKARA) güneyindeki tortul istifin sedimanter petrolojik incelenmesi. MTA Dergi no:89, 99-117.

Gönenç, O., 1978. Haymana-Polatlı havzasının batı kesiminin jeolojisi ve petrol olanakları. MTA rapor no:6396.

Görür, N., 1981. Tuzgölü-Haymana Havzasının stratigrafik analizi. Anadolunun Jeolojisi Sempozyumu, TJK 35. Bilimsel ve Teknik Kurultay Bildiriler Kitab1, 60-65.

Görür, N., ve Derman, A.S., 1978. Tuzgölü-Haymana Havzasının stratigrafik ve tektonik analizi. TPAO Raporu, No. 1514, 60s (yayımlanmamış).

Loverson, A.I., 1967. Geologie of Petroleum. W.H. Free and Comp., San Fransisco, 703 pp.

Norman, T., 1972. Ankara Yahşihan bölgesinde Üst Kretase-Alt Tersiyer istifinin stratigrafisi. TJK Bülteni, XV (2), 180-277.

Oktay, F. Y., ve Dellalolu A. A., 1987. Tuz Gölü havzası (Orta Anadolu) stratigrafisi üzerine yeni görüşler. 7. Petrol Kongresi Bildiriler Kitab1, 312-321.
Okay, A.I., and Altıner, D., 2016. Carbonate sedimentation in an extensional active margin: Cretaceous history of the Haymana region, Pontides. International Journal of Earth Sciences, 105(7), 2013-2030

Rigo de Righi, M., and Cortesini, A., 1960. Regional studies, Central Anatolian basin, Progres Report, I. Turkish Gulf Oil Co., 14s (yayımlanmamış).

Roth, P.H., 1978. Cretaceous nannoplankton biostratigraphy and oceanography of the $\mathrm{N}$. Western Atlantic Ocean (DSDP Leg 44). Initial Reports of the Deep Sea Drilling Project, 44, 731759 .

Sirel, E., 1975. Polatlı (GB Ankara) güneyinin stratigrafisi. TJK Bülteni, 18 (2), 181-192

Sonel, N., Kulke, H., Sarı, A., Acar, A., Ayyıldız, T., Kadığlu, Y., Özkul, M., Yıldız, A., Doğan, A.u., Habo, M., Paeghe, W. ve Doğan, M., 1996. Tuz Gölü Havzasının Jeolojisi ve Hidrokarbon Potansiyelinin Değerlendirilmesi Projesi Ara Raporu. TPAO rapor no:2452.

Sonel, N., 2001. Petrol ve Yeralt1 Jeolojisi kitab1. Ankara Üniversitesi Mühendislik Fakültesi Jeoloji Mühendisliği Bölümü, Ankara, 312 s.

Toker, V., 1979. Haymana yöresi (GB Ankara) Nannoplankton biyostratigrafisi. TJK Bült., 23, 165-177.

Sengor, A.M.C. and Yilmaz, Y., 1981. Tethyan evolution of Turkey: a plate tectonic approach. Tectonophysics, 75: 181-241.

Toker, V., 1979a. Haymana ve Kavaklı formasyonları Üst Kretase planktonik foraminifer ve nannoplanktonlar. TÜBTAK Araştırma Kurulu VI. Bilim Kongresi Bildiriler Kitab1, 57-70.

Toker, V., 1979b. Haymana yöresi Üst Kretase planktonik foraminiferleri ve biyostratigrafi incelemesi. TJK Bülteni, 22, 12-132.

Turgut, S., 1978. Tuzgölü Havzasının stratigrafik ve çökelsel gelişmesi. Türkiye 4. Petrol Kongresi Bildirileri, 115-126

Turkish Gulf Oil Company, 1961. Orta Anadolu da Tuz Gölü Baseninin bölgesel jeolojisi ve yapılan petrol aramalar. Petrol faaliyeti 6, Ankara, 31-34.

Uğurtaş, G., 1975. Geophysical interpretation of part of the Tuzgolu basin. MTA Bülteni, 38-44. 
Ünalan, G., Yüksel, V., Tekeli, T., Gönenç, O., Seyirt, Z., ve Hüseyin, S., 1985. Haymana-Polatlı havzasının jeolojisi ve prospeksiyon raporu. MTA Derleme no: 7665.

Ünalan, G., ve Yüksel, V., 1985. Haymana-Polatl1 havzasının jeolojisi ve petrol olanaklar. MTA Raporu, No. 7665, 59s (yayımlanmamış).

Ünalan, G., Yüksel, V., Tekeli, T., Gönen, O., Seyirt, Z., ve Hüseyin, S., 1976. Haymana-Polatlı yöresinin (GB Ankara) Üst Kretase-Alt Tersiyer stratigrafisi ve paleocografik evrimi. TJK Bülteni, 19, 159-176
Üşenmez, Ş., 1996. Karbonat Kayaçların Sinıflandırılması.Yozgat Mühendislik-Mimarlık Fakültesi, Yozgat, $435 \mathrm{~s}$.

Yüksel, S., 1970. Etude geologique de la region de Haymana (Turquie Centrale) These. Faculte des Sciences de Lunversite de Nancy, France, 77p.

Yüksel, S., 1973. Haymana yöresi tortul dizisinin düşey yönde gelişimi ve yanal fasiyes dağılımı. MTA Dergisi, 80, 50-53.

Yüksel, V., 1978. Haymana-Polatlı havzasının Jeolojisi ve Petrol Olanakları. MTA rapor no:7665. 